\title{
A 50 year natural history of an untreated myelomeningocele - a rare
}

\section{case}

\author{
Claus Mosdal*, Mikkel Mylius Rasmussen and Dorte Clemmensen
}

\author{
Address: Neurosurgical department, Aarhus University Hospital, Denmark \\ Email: Claus Mosdal* - cmo@ask.dk \\ * Corresponding author
}

\author{
from 53rd Annual Meeting of the Society for Research into Hydrocephalus and Spina Bifida \\ Belfast, UK. 24-27 June 2009 \\ Published: 27 November 2009 \\ Cerebrospinal Fluid Research 2009, 6(Suppl 2):S44 doi:10.1186/1743-8454-6-S2-S44
}

This abstract is available from: http://www.cerebrospinalfluidresearch.com/content/6/S2/S44

(c) 2009 Mosdal et al; licensee BioMed Central Ltd.

\section{Case report}

An almost 50 year old woman, admitted to our clinic very recently, born with a small lumbo-sacral myelomeningocele (MMC), bilateral pes equino-varus and paralysed feet. The father refused any treatment. However, she survived, grew up, became able to walk with crutches and to bicycle. Bladder emptying was by means of abdominal pressure, later by means of a Bricker-bladder. She went through ordinary school and further education, but lost gradually walking ability and became wheel-chair-bound. She became married and had two healthy children by Caesarean section. She is now employed as leader of the secretariat in an educational institution on normal conditions.

In the meantime the MMC has grown slowly to the actual size of approximately $60 \times 40 \times 30 \mathrm{~cm}$. She can lie on both sides, but most of her life is in the sitting position.

She now asks for surgical treatment. Because of time, we haven't done surgery yet, and because of contractures in hips and knees and the size, we will have to drain the MMC before MR scan to plan the operation that will take place in April. Subsequently we will have to deal with the potential hydrocephalus (VP-shunt? 3rd ventriculostomy?) 